\title{
A Rare Case of Contiguous Three-level Lumbar Burst Fractures-treated with Combined Posterior Stabilization and Anterior Fusion
}

\author{
Charanjit Singh Dhillon ${ }^{1}$, Ahamed Shafeek Nanakkal ${ }^{1}$, Nilay Prafulsinh Chhasatia ${ }^{1}$, Narendra \\ Reddy Medagam ${ }^{1}$, Anandkumar Khatavi ${ }^{1}$
}

Learning Point of the Article:

Multilevel contiguous lumbar burst fractures are rare and may require combined surgical approaches fro optimal treatment.

\section{Abstract}

Introduction: Burst fractures occur frequently in high energy trauma and are commonly associated with falls from height and road traffic accidents. While multiple burst fractures are not uncommon in thoracic spine, three or more contiguous level burst fractures are a relative rarity especially, in lumbar spine. The treatment of multilevel burst fractures must be individualized, and each fracture should be treated according to its inherent stability. To the best of our knowledge, this is the only case of such injury reported in English literature.

Case Report: A 17-year-old girl who sustained contiguous three-level lumbar burst fractures with neurological compromise following alleged history of fall from height. Radiographs/computed tomography scan revealed burst fractures of L2, L3, and L4 vertebrae with retropulsion of bony fragments at all the levels. Patient underwent minimally invasive posterior stabilization and anterior Hemi-corpectomy of L2, L4, and fusion. The patient recovered completely from neurological deficits by the end of 6 months.

Conclusion: Multiple contiguous burst fractures in the lumbar spine are a rare entity. To the best of our knowledge, this is the only case of such injury reported in English literature. The treatment requires a thorough assessment of the fracture pattern and often requires a combination of surgical approaches. Each fracture merits treatment based on individual characteristics of fracture patterns and the amount of canal compromise at each level.

Keywords: Lumbar, burst fracture, multiple, contiguous.

\section{Introduction}

Burst fractures occur frequently in high energy trauma and are commonly associated with falls from height and road traffic accidents [1]. Although consensus regarding surgical indications and choices of approaches is still evolving, unstable burst fractures associated with neurological involvement are usually treated with surgery. While multiple burst fractures are not uncommon in the thoracic spine, three or more contiguous burst fractures are a relative rarity, especially in the lumbar spine. In this report, we present the case of a patient with contiguous three-level lumbar burst fractures following a fall from height. To the best of our knowledge, this is the only case of such injury reported in English literature.

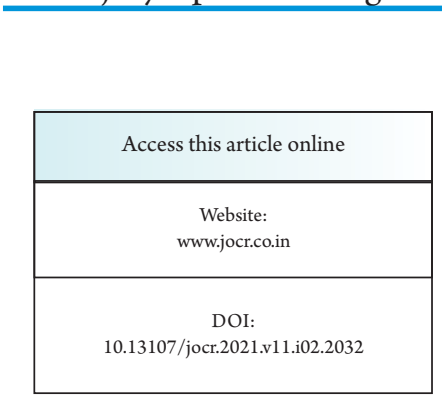

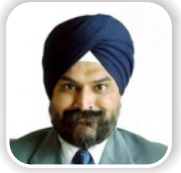

Dr. Charanjit Singh Dhillon

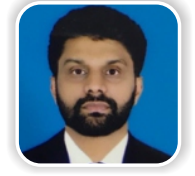

Dr. Ahamed Shafeek Nanakkal

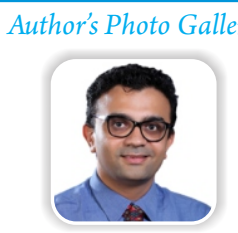

Dr. Nlay Prafulsinh Chhasatia

\section{Case Report}

We present a case of a 17-year-old girl with burst fractures of L2, L3, and L4 vertebrae with neurological compromise. The patient presented to the emergency department with an alleged history of fall from height (10 feet) at school, followed by sudden onset weakness of both lower limbs. There was no history of loss of consciousness, vomiting, ear, nose, throat bleed, or seizures. She was shifted from her residence to the emergency department in our hospital on spine board by qualified paramedical staffs.

On arrival, she was conscious, oriented, and her vital parameters
${ }^{1}$ Department of Spine, FNB Spine Surgery, Miot Hospital, Chennai, Tamil Nadu, India.

Department of Spine, FNB Spine Surgery, Miot Hospital, Chennai - 600 089, Tamil Nadu, India.

E-mail: drshafeekn@gmail.com

Journal of Orthopaedic Case Reports | pISSN 2250-0685 | eISSN 2321-3817 | Available on www.jocr.co.in | doi:10.13107/jocr.2021.v11.i02.2032 This is an Open Access article distributed under the terms of the Creative Commons Attribution Non-Commercial License (http://creativecommons.org/licenses/by-nc/3.0) which permits unrestricted non-commercial use, distribution, and reproduction in any medium, provided the original work is properly cited. 


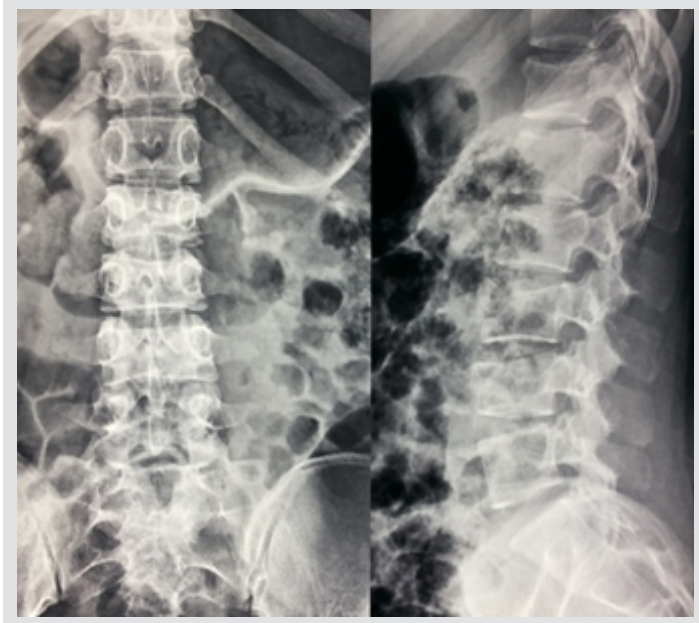

Figure 1: X-ray lumbosacral spine demonstrating loss of vertebral height at L2, L3, and L4 vertebrae.

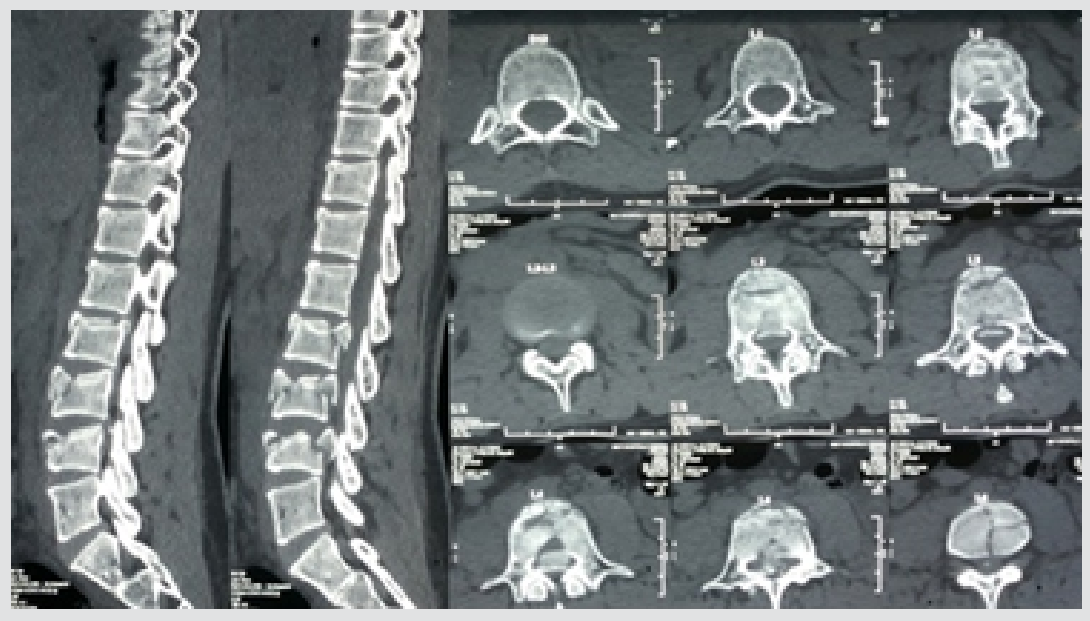

Figure 2: $\mathrm{CT}$ can reveals burst fractures of L2, L3, and L4 vertebrae with retropulsion of posterior cortex with $80 \%$ canal occlusion at L4 level, $50 \%$ canal occlusion at L2 level, and $30 \%$ canal occlusion at $\mathrm{L} 3$ level.. were stable. She did not have any external injury or bony tenderness over limbs except deep tenderness over lumbar spine. Neurological examination revealed bilateral foot drop and toe extensor weakness. Bladder incontinence was noted during transfer by paramedics and a urinary catheter was placed. Lumbar spine radiographs indicated loss of vertebral height at L2, L3, and L4 vertebrae (Fig. 1). Computerized tomography scan of lumbar spine revealed burst fractures of L2, L3, and L4 vertebrae with the involvement of both anterior and middle columns with retropulsion of bony fragments at all the levels (Fig. 2). There was large retropulsed fragment at L4 level causing $80 \%$ canal encroachment. Small retropulsed fragments at L2 and L3 level were seen causing 50\% and 30\% canal encroachment, respectively. Magnetic resonance imaging scan reported thecal sac compression with retro pulsed fragments at all the three levels (Fig. 3). Patient was planned for minimally invasive posterior stabilization and anterior hemi-corpectomy of L2, L4, and fusion. Since the retropulsed fragment at L3 was not causing significant canal compromise, it was decided to spare L2-L3 disc.

And lateral views showing loss of vertebral heights at L2, L3, and L4 vertebrae.

There is $80 \%$ canal occlusion at L 4 level, $50 \%$ canal occlusion at L2 level, and 30\% canal occlusion at L3 level.

\section{Procedure}

Patient was positioned prone under general anesthesia. Cannulated $6.5 \mathrm{~mm}$ pedicle screws were inserted in L1 and L5 pedicles on either side percutaneously under C-arm guidance
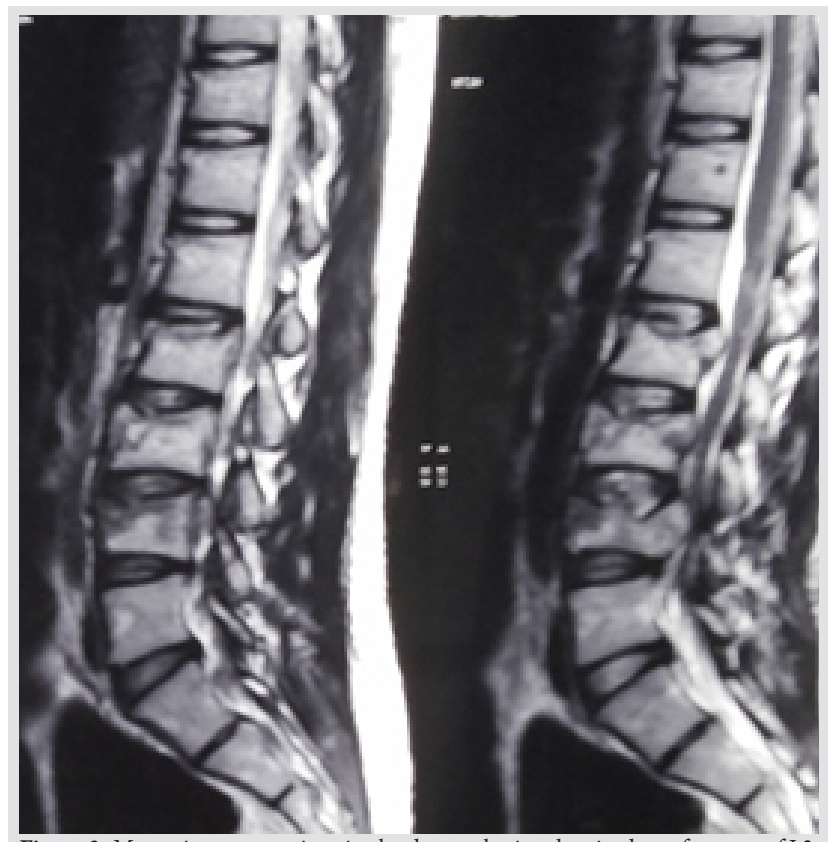

Figure 3: Magnetic resonance imaging lumbosacral spine showing burst fractures of L2, $\mathrm{L} 3$, and L4 vertebral bodies with marrow edema and retropulsion of fracture and fragments causing central canal compromise, severe at L4 level impinging cauda equina.

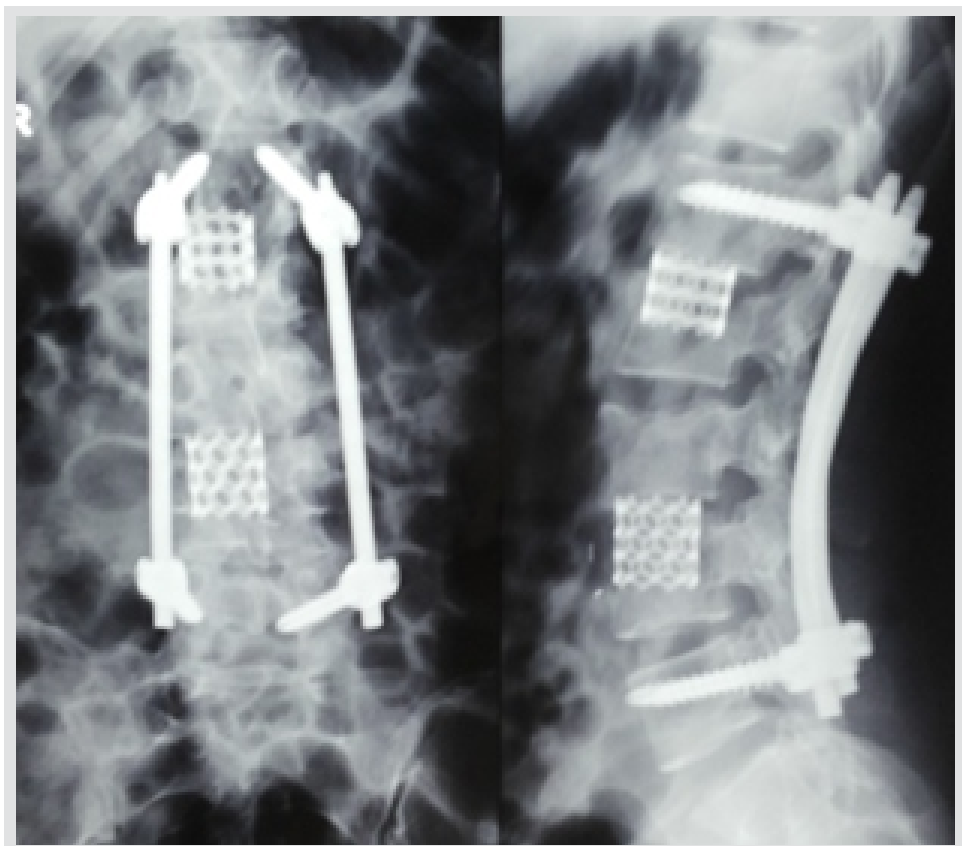

Figure 4: Post-operative X-ray showing minimally invasive posterior stabilization from L1 to L5, partial corpectomy with cage reconstruction at $\mathrm{L} 2$ and $\mathrm{L} 4$ levels with sounf fusion is seen. 
(Longitude ${ }^{\mathrm{Tx}}$, Medtronic, Minneapolis, USA). Pre-contoured rods were inserted through separate stab incision above the cephalad pedicle screws and slid in a controlled manner into the tulips of $L 1$ and $L 5$ pedicle screws. Once the position of the rods was confirmed, the set screws were tightened to the tulips to complete the construct. Wound closed in standard fashion.

Patient was then re-positioned in a right lateral position. Anterior retroperitoneal approach was utilized to expose L1 to L4 vertebrae. L1-L2 and L3-L4 discs were identified with image intensifier and excised with the help of rongeurs and bone nibblers. Partial corpectomies of superior one-third of L2 and L4 vertebrae were done to expose the retropulsed bony fragments. Retropulsed bony fragments were removed and dura was decompressed. The adequacy of dural decompression was confirmed by palpating the dura with Penfield Dissector from near pedicle to far pedicle. End plates were prepared and the hemicorpectomy defect was reconstructed with appropriate size titanium mesh cage filled with bone graft. The stability of the cages was confirmed on table and the position was verified under image intensifier. Wound was closed in layer over subfascial drain.

Postoperatively patient was mobilized with lumbosacral belt aided by ankle-foot orthosis (AFO) for the bilateral foot drops. She underwent aggressive physiotherapy and rehabilitation under the care of the physiotherapy department. At 3 months, she was able to walk with single elbow crutch with AFO. At 6 months, she recovered completely neurologically and was able to walk without support as well as manage stairs without aids. Follow-up X-ray at 6 months documented sound fusion at L1L2 and L3-L4 levels with the presence of a bony bridge anterior to the cages (sentinel sign). L3 fracture also healed satisfactorily (Fig. 4). The patient also recovered bowel and bladder function by the end of 9 months. Posterior implant removal was done after 1 year to regain movements at unfused L2-L3 and L4-L5 levels.

\section{Discussion}

Denis [2] has described burst fractures as failure of anterior and middle columns with retropulsion of bony fragments into the vertebral canal. Burst fractures resulting from axial compressive load occur in $10-20 \%$ of all the spine fractures [3]. Most common anatomical location for burst fractures is the thoracolumbar junction, where the stiff thoracic spine meets the more flexible lumbar spine. Burst fractures of the lower lumbar spine, due to its flexible biomechanics, represent a smaller subset of all spine fractures $[4,5]$.

Due to the considerable forces acting on the vertebrae in the higher velocity injuries, multiple burst fractures are commonly seen and are more often non-contiguous $[6,7,8]$. Patients presenting with thoracolumbar injury require a thorough evaluation to detect any other spine injury, incidence of which can be as high as 25\% [9]. Contiguous level burst fractures in dorsal and cervical spine are reported [10]. We did an extensive literature review for contiguous level lumbar burst fracture using keywords, "lumbar", "burst", "multiple", and "contiguous" in Pubmed database. Two cases of two-level contiguous lumbar burst fractures have been reported previously. Youssef et al. described seizure associated two-level contiguous lumbar burst fracture [11] and Motsitsi et al reported two-level contiguous lumbar burst fracture following direct trauma to the spine. However, to the best of our knowledge, there are no case reports of contiguous lumbar burst fractures involving three levels.

The treatment goals for patients with lumbar spinal injuries are to maintain or restore spinal alignment and stability, decompress to promote neurologic function, mobilize the patient, and start rehabilitation as soon as possible [12, 13]. There is debate as to optimal treatment of the lower lumbar burst fractures $[14,15]$. Surgical treatment options for management include a posterior alone, anterior alone, or combined anterior, and posterior approaches $[16,17,18,19]$. Long segment posterior stabilization and fusion surgeries should be avoided to conserve motion segments in the lumbar spine [20]. Posterior "short segment" fixation can avoid fusing multiple levels in the lumbar spine, but are prone to serious complications. Higher rate of implant failure ranging from $9 \%$ to $54 \%$, pseudarthrosis, infection, and increase in kyphosis reported in the literature due to lack anterior column supports $[21,22,23]$. In a prospective study by Korovessis et al. compared the results of the combined anterior-posterior surgery with posterior "short-segment" transpedicular fixation and found that although intermediate screws were inserted in the fractured vertebra, the resultant construct did not prevent the average $5^{\circ}$ loss of correction at the final evaluation [3]. Combined anterior and posterior surgical approaches provide improved sagittal alignment, immediate, and complete neural decompression for optimum recovery of neural function, and stabilization of the disrupted posterior ligamentous complex [24]. In our institute, any patients with burst fractures without neurological deficits and with a retropulsed fragment causing $<50 \%$ canal compromise is managed with posterior stabilization alone. Anterior decompression and reconstruction are reserved for patients with canal compromise of more than $50 \%$ with neurological deficits or with severely comminuted anterior vertebral body $[25,26]$. Since this patient had unstable three-level burst fracture with canal compromise, we proceeded with minimally invasive posterior stabilization and anterior partial corpectomy at L2 and L4 levels where canal compromise was more than $50 \%$.

In summary, patients with multilevel burst fractures require a 
careful clinical and neurological assessment. The treatment of multilevel burst fractures must be individualized, and each fracture should be treated according to its inherent stability.

\section{Conclusion}

Multiple contiguous burst fractures in the lumbar spine are a rare entity. The treatment requires a thorough assessment of the fracture pattern and often requires a combination of surgical approaches. Each fracture merits treatment based on individual characteristics of fracture pattern and the amount of canal compromise at each level.

\section{References}

1. Bensch FV, Koivikko MP, Kiuru MJ, Koskinen SK. The incidence and distribution of burst fractures. Emerg Radiol 2006; 12:124-9.

2. Denis F. The three column spine and its significance in the classification of acute thoracolumbar spinal injuries. Spine (Phila Pa 1976) 1983;8:817-31.

3. Korovessis P, Baikousis A, Zacharatos S, Petsinis G, Koureas G, Iliopoulos P. Combined anterior plus posterior stabilization versus posterior short-segment instrumentation and fusion for mid-lumbar (L2-L4) burst fractures. Spine (Phila Pa 1976) 2006;31:859-68.

4. Levine MA, Edwards CC. Low lumbar burst fractures. Reduction and stabilization using the modular spine fixation system. Orthopedics 1988;11:1427-32.

5. Mick CA, Carl A, Sachs B, Hresko MT, Pfeifer BA. Burst fractures of the fifth lumbar vertebra. Spine (Phila Pa 1976) 1993;13:1878-84.

6. Cassar-Pullicino VN. Spinal injury: Optimising the imaging options. EurJ Radiol 2002;42:85-91.

7. Bensch FV, Kiuru MJ, Koivikko MP, Koskinen SK. Spine fractures in falling accidents: Analysis of multidetector CT findings. Eur Radiol 2004;14:618-24.

8. Daffner RH, Daffner SD. Vertebral injuries: Detection and implications. EurJ Radiol 2002;42:100-16.

9. Calenoff L, Chessare JW, Rogers LF, Toerge J, Rosen JS. Multiple level spinal injuries: Importance of early recognition. AJRAm J Roentgenol 1978;130:665-9.

10. Han SR, Sohn MJ. Twelve contiguous spinous process fracture of cervico-thoracic spine. Korean J Spine 2014;11:212-3.

11. Youssef JA, McCullen GM, Brown CC. Seizure-induced lumbar burst fracture. Spine (Phila Pa 1976) 1995;20:1301-3.

12. Seth KW. Thoracic and Lumbar Spinal Injuries Taken from

\section{Clinical Message}

Multiple contiguous burst fractures in lumbar spine are a rare entity. We present the case of a patient with contiguous three level lumbar burst fractures following a fall from height. To the best of our knowledge, this is the only case of such injury reported in English literature. The treatment requires thorough assessment of the fracture pattern and often requires a combination of surgical approaches. Treatment of each fracture is individualized and depends on fracture patterns. the Spine by Rothman-Simeone. 6th ed. Amsterdam: Elsevier; 2011.

13. Tsirikos AI, Saifuddin A, Noordeen MH, Tucker SK. Traumatic lumbosacral dislocation. Spine (Phila Pa 1976) 2004;29:E164-8.

14. Bradford DS, Akbarnia BA, Winter RB, Seljeskog EL. Surgical stabilization of fractures and fracture-dislocations of the thoracic spine. Spine 1977;2:185-6.

15. Huang TJ, Chen JY, Shih HN, Chen YJ, Hsu RW. Surgical indications in low lumbar burst fractures: Experiences with anterior locking plate system and the reduction-fixation system.J Trauma 1995;39:910-4.

16. Gurwitz GS, Dawson JM, McNamara MJ, Federspiel CF, Spengler DM. Biomechanical analysis of three surgical approaches for lumbar burst fractures using short-segment instrumentation. Spine (Phila Pa 1976) 1993;18:977-82.

17. Kaneda K, Abumi K, Fujiya M. Burst fractures with neurologic deficits of the thoracolumbar-lumbar spine: Results of anterior decompression and stabilization with anterior instrumentation. Spine (Phila Pa 1976) 1984;9:788-95.

18. Sasso RC, Best NM, Reilly TM, McGuire RA Jr. Anterioronly stabilization of three-column thoracolumbar injuries. J Spinal Disord Tech 2005; 18:S7-14.

19. Waqar M, Van-Popta D, Barone DG, Bhojak M, Pillay R, Sarsam Z. Short versus long-segment posterior fixation in the treatment of thoracolumbar junction fractures: $A$ comparison of outcomes. BrJ Neurosurg 2016;31:54-7.

20. An HS, Simpson JM, Ebraheim NA, Jackson WT, Moore J, O'Malley NP. Low lumbar burst fractures: Comparison between conservative and surgical treatments. Orthopedics 1992;15:367-73.

21. Rechtine GR, Bono PL, Cahill D, Bolesta MJ, Chrin AM. Postoperative wound infection after instrumentation of thoracic and lumbar fractures. J Orthop Trauma 
2001;15:566-9.

22. McLain RF, Sparling E, Benson DR. Early failure of shortsegment pedicle instrumentation for thoracolumbar fractures. A preliminary report. J Bone Joint Surg Am 1993;75:162-7.

23. Schnee CL, Ansell LV. Selection criteria and outcome of operative approaches for thoracolumbar burst fractures with and without neurological deficit. J Neurosurg 1997;86:48-55.

24. Wike HJ, Kemmerich V, Claes LE, Arand M. Combined anteroposterior spinal fixation provides superior stabilisation to a single anterior or posterior procedure. J Bone Joint Surg Br 2001;83:609-17.

25. Haas N, Blauth $M$, Tscherne $H$. Anterior plating in thoracolumbar spine injuries. Indication, technique, and results. Spine (Phila Pa 1976) 1991;16 Suppl3:S100-11.

26. McDonough PW, Davis R, Tribus C, Zdeblick TA. The management of acute thoracolumbar burst fractures with anterior corpectomy and Z-plate fixation. Spine (Phila Pa 1976) 2004;29:1901-8; discussion 1909.
Conflict of Interest: Nil

Source of Support: Nil

Consent: The authors confirm that informed consent was obtained

from the patient for publication of this case report

\section{How to Cite this Article}

Dhillon CS, Nanakkal AS, Chhasatia NP, Medagam NR, Khatavi A. A Rare Case of Contiguous Three-level Lumbar Burst Fractures-treated with Combined Posterior Stabilization and Anterior Fusion. Journal of Orthopaedic Case Reports 2021 February; 11(2): 71-75. 